\title{
ANALISIS PERFORMANSI KINERJA SERVER MENGGUNAKAN TERMINAL SERVER BERBASIS WINDOWS DAN LINUX (Studi Kasus STMIK STIKOM Indonesia)
}

\author{
I Kadek Susila Satwika'), I Dewa Putu Gede Wiyata Putra ${ }^{2)}$ \\ 1), 2) Program Studi Sistem Computer, STMIK STIKOM Indonesia \\ Jl Tukad Pakerisan no 97, Panjer, Kec. Denpasar Selatan, Denpasar - Bali 80225 \\ Email : susila.satwika@stiki-indonesia.ac.id ${ }^{1)}$, dewa.wiyata@ stiki-indonesia.ac.id ${ }^{2)}$
}

\begin{abstract}
Abstrak
Teknologi jaringan komputer saat ini menjadi kebutuhan yang wajib ada di setiap instansi dan perusasahaan. Dengan adanya jaringan komputer dapat membantu untuk meringankan pekerjaan manusia. Dampak dari perkembangan jaringan komputer ini salah satunya dirasakan oleh seluruh instasi dan perusahaan. Salah satunya adalah pada proses praktikum pada kampus STMIK STIKOM Indonesia. Banyaknya aplikasi yang digunakan serta banyaknya jumlah komputer pada lab membuat proses maintenance memakan waktu yang sangat lama. Dikarenakan proses install dan update dilakukan satu persatu di masing-masing komputer. Permasalahan ini dapat diatasi dengan teknologi cloud computing berbasis IaaS (Infrastructure as a Services). Penelitian ini membuat dan menganalisa terminal server menggunakan server windows dan linux. Dengan adanya terminal server dapat mempermudah maintenance karena hanya dilakukan pada server. Adapun parameter yang diukur pada penelitian adalah penggunaan RAM (Random Access Memory), CPU (Central Processor Unit), Trafik, dan Disk pada server. Hasil dari penelitian adalah, penggunaan resource menggunakan server linux lebih rendah jika dibandingkan dengan server windows. Kemudian jumlah client menggunakan server linux lebih banyak dibandingkan dengan server windows.
\end{abstract}

Kata kunci: Terminal Server, Cloud Computing, Server.

\section{Abstract}

Computer network technology is now a mandatory requirement in every agency and company. With the existence of a computer network can help to alleviate human work. The impact of the development of computer networks is one of them felt by all instances and companies. One of them is in the practicum process at the STMIK STIKOM Indonesia campus. The number of applications used and the large number of computers in the lab makes the maintenance process takes a very long time. Because the install and update process is done one by one on each computer. This problem can be overcome by IaaS (Infrastructure as a Services) based cloud computing technology. This research creates and analyzes a terminal server using Windows and Linux servers. With the terminal server, it can simplify maintenance because it is only done on the server. The parameters measured in this study are the use of RAM (Random Access Memory), CPU (Central Processor Unit), Traffic, and Disk on the server. The results of the study are, the use of resources using Linux servers is lower when compared to Windows servers. Then the number of clients using Linux servers more than Windows servers.

Keywords: Terminal Server, Cloud Computing, Server.

\section{PENDAHULUAN}

Melihat banyaknya dan kompleksnya aplikasi pada sebuah perusahaan membuat tim IT atau teknisi memiliki pekerjaan yang cukup banyak untuk melakukan perawatan pada aplikasi tersebut. Dimana team IT atau teknisi akan menginstall dan mengupdate aplikasi pada masingmasing PC yang sudah terinsatall aplikasi. Banyaknya jumlah PC yang ada pada sebuah perusahaan cukup membuat team IT atau teknisi kerepotan ketika ada aplikasi yang harus diinstall ataupun diupdate. Dimana tim IT atau teknisi akan melakukan install atau update pada seluruh PC yang memerlukan aplikasi tersebut. Dapat dibayangkan jika terdapat 50 PC pada perusahaan, maka team IT atau teknisi akan melakukan install dan update pada 50 PC tersebut. Hal ini sangat 
tidak efisien dari sisi waktu yang mengakibatkan kinerja pada perusahaan tersebut menjadi terganggu. Salah satu institusi yang mengalami permasalahan tersebut adalah STMIK STIKOM Indonesia.

Permasalahan tersebut dapat diatasi dengan mengembangkan sebuah sistem computer client-server berbasis terminal server dan menjadi tempat penyimpanan semua aplikasi yang digunakan untuk melakukan praktikum. Sehingga nantinya tidak perlu menginstall aplikasi di masing PC yang ada di laboratorium, karena cukup diinstall pada satu computer server. Terminal Server merupakan sebuah teknologi jaringan diskless (tanpa hardisk) yang memungkinkan kita membuat suatu jaringan terpusat pada satu server. Sistem ini mampu memberikan efisiensi dalam melakukan maintenance aplikasi, dimana nantinya untuk melakukan proses update tidak perlu dilakukan di masing-masing computer. Proses update hanya dilakukan pada computer server. Selain itu dari sisi keamanan pada sisi computer client akan terjamin. Dikarenakan aplikasi semuanya terdapat pada computer server. Berbagai referensi yang mengacu pada penelitian ini [1][2][3] menyebutkan bahwa penggunaan jaringan berbasis cloud computing mampu memberikan efisiensi yang lebih baik dalam hal skalabiltas jaringan dan biaya. Kemudian penelitian lain [4][5][6] menyebutkan dengan menggunakan metode cloud computing menunjukkan adanya penghematan yang signifikan dari sisi biaya pengadaan dan pemeliharaan baik secara fisik maupun aplikasi. Berdasarkan hasil penelitian tersebut maka penelitian ini menerapkan sistem cloud computing pada laboratorium STMIK STIKOM Indonesia guna membantu proses kegiatan praktikum.

Penelitian ini dimulai dengan membangun sistem terminal server menggunakan 2 operating system (OS) yaitu Windows dan Linux. Kemudian dilakukan perbandingan performance antara terminal server berbasis Windows dengan terminal server berbasis Linux. Parameter yang diukur adalah penggunaan memory (RAM) serta hardisk pada computer server, serta melakukan pengukuran throughput pada server.

\section{DASAR TEORI}

\section{a. Jaringan Client-Server}

Jaringan client-server menghubungkan computer server dengan computer klien/workstation. Computer server adalah computer yang menyediakan fasilitas bagi computercomputer klien/ workstation yang terhubung dalam jaringan. Sedangkan computer klien adalah computer yang menggunakan fasilitas yang disediakan oleh computer server. Computer server pada jaringan klien server disebut dengan Dedicated Server, karena computer server yang digunakan hanya sebagai penyedia fasilitas untuk computer klien/ workstation. Computer server tidak dapat berperan sebagai computer klien/workstation. Gambar 1 menunjukkan model jaringan Client-Server.

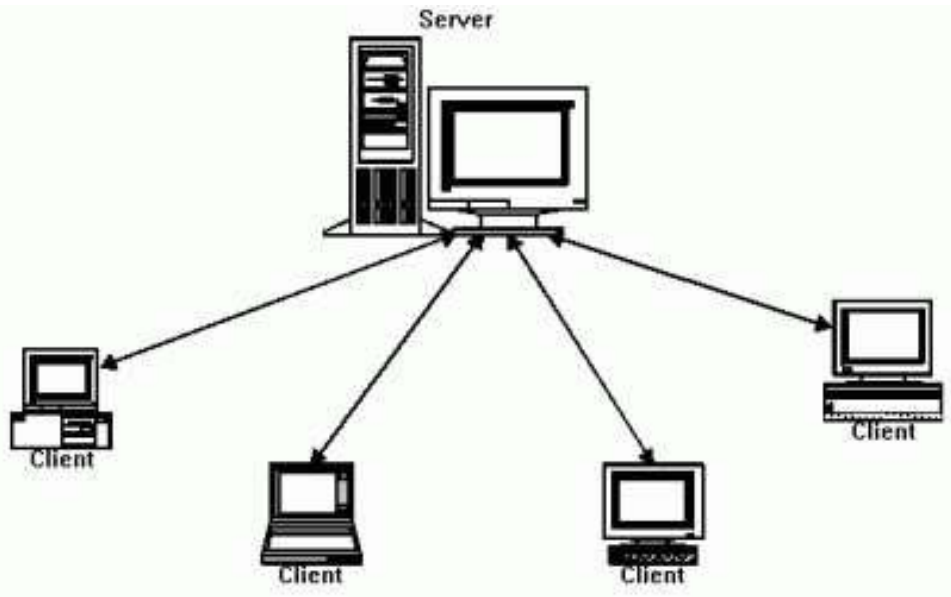

Gambar 1. Jaringan Client-Server

\section{b. Terminal Server}

Terminal server adalah sebuah aplikasi server yang memperbolehkan lebih dari satu user mengakses server dan dapat menjalankan system operasi juga aplikasi-aplikasi yang ada pada 
server. Setiap pemakai akan mendapatkan antarmuka desktop mulai dari sesi login dan dapat mengakses aplikasi, data dan seluruh sumberdaya yang ada dan terpasang pada computer server. Semua user yang login ke server dapat menjalankan computer masing-masing secara independen, artinya walaupun client lebih dari satu, masing-masing client dapat melakukan proses masingmasing secara mandiri tanpa dipengaruhi client lain.

\section{c. Cloud Computing}

Cloud computing atau komputasi awan merupakan istilah baru dalam dunia komputasi sehingga memiliki banyak definisi. Namun begitu, definisi dari The US National Institute of Standards and Technology (NIST) sepertinya paling mencakupi aspek-aspek umum dari cloud computing yang disetujui oleh berbagai pihak. Model layanan berbasis cloud computing dapat berupa Software as a Services (SaaS), Platform as a Services (PaaS), dan Infrastructure as a Services (IaaS). Sedangkan model implementasi berbasis cloud computing dapat berupa Private Cloud, Community Cloud, Public Cloud, dan Hybrid Cloud [7].

On-demand self-service berarti pengguna dapat mengatur kapabilitas layanan, seperti waktu layanan dan kapasitas penyimpanan, yang ingin digunakan secara mandiri dan otomatis tanpa ada interaksi dengan penyedia layanan. Broad network access berarti kapabilitas layanan dapat diakses melalui jaringan menggunakan berbagai perangkat sebagai client, misalnya PC, smartphone, laptop, dan PDA. Resource pooling berarti sumberdaya komputasi yang dimiliki oleh penyedia layanan dikumpulkan untuk melayani banyak pengguna dengan model multi-tenan. Rapid elasticity berarti kapabilitas dari layanan dapat ditingkatkan dengan cepat dan fleksibel. Measured service berarti sumberdaya yang digunakan dapat dikendalikan dan dioptimasi secara otomatis menggunakan suatu mekanisme pengukuran tertentu.

\section{d. Jaringan Computer Diskless}

Jaringan Computer diskless merupakan suatu jaringan computer yang dapat beroperasi tanpa adanya media penyimpanan. Semua penyimpanan data disimpan pada sisi server. Computer client diaktifkan dengan mengambil file dari computer server sehingga pada sisi client tidak ada penyimpanan data sama sekali. Untuk mengenali computer-computer dalam jaringan tersebut satu dengan yang lainnya terdapat informasi yang unik. Informasi unik tersebut adalah MAC address. Protocol yang digunakan adalah BOOTP dan DHCP. Dengan demikian computer client harus terdaftar dalam suatu database. Ketika computer client dijalankan maka computer mendownload informasi kernel yang ada pada server dengan menggunakan protocol TFTP (Trivial File Transfer Protocol). Ketika kernel berhasil di-download, kernel kemudian melakukan inisialisasi perangkat keras yang dimiliki computer client. Akhirnya, computer client membutuhkan file sistem root, yang diambil dari server menggunakan protocol NFS (Network File Server). Dengan NFS, computer client dapat menjalankan sistem server melalui jaringan [8].

\section{METODOLOGI PENELITIAN}

Sistem yang akan dibangun dalam penelitian ini adalah Sistem terminal server yang menggunakan metode IaaS (Infrastructure as a Services) berbasis Terminal Server. Satu computer akan berfungsi sebagai server tempat menyimpan semua aplikasi. Computer client nantinya dalam penggunaannya akan mengakses computer server. Sistem ini mampu memberikan efisiensi dalam melakukan maintenance aplikasi, dimana nantinya untuk melakukan proses update tidak perlu dilakukan di masing-masing computer. Gambar 2 menunjukkan gambaran umum perencanaan sistem client-server.

Selain yang disebutkan diatas, pada penelitian ini juga akan melakukan pengukuran unjuk kerja server dengan parameter penggunaan memori (RAM) dan Hardisk serta pengukuran unjuk kerja jaringan dengan parameter throughput, dengan membandingkan kinerja terminal server menggunakan windows server dan Linux server. Penelitian ini juga memberikan referensi jumlah kebutuhan server yang diperlukan untuk melaksanakan kegiatan praktikum dengan jumlah PC client sebanyak 30 PC. 


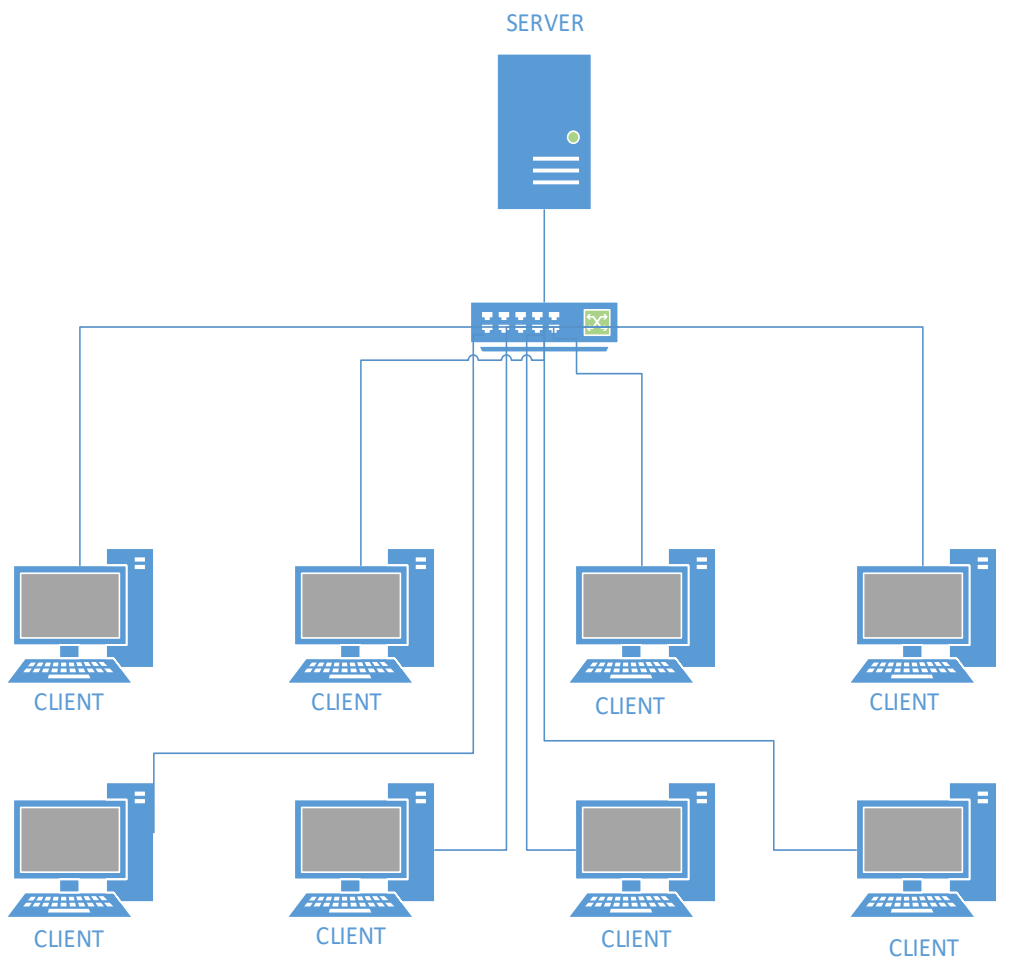

Gambar 2 Sistem Client Server Di Laboratorium

\section{HASIL DAN PEMBAHASAN}

Pada tahap ini dilakukan pengujian terhadap terminal server. Pengujian ini dilakukan dengan melakukan 4 tahap pengujian. Pengujian pertama dilakukan dengan menguji saat computer client melakukan booting dengan variasi jumlah PC. Kemudian dilakukan pengujian dengan menjalankan aplikasi Cisco Packet Tracer dimana aplikasi ini digunakan saat melakukan praktikum di lab Jaringan Computer. Pengujian dengan menjalankan aplikasi ini dilakukan dengan variasi jumlah router yaitu 2 router, 4 router, dan 8 router. Adapun parameter yang diukur dalam penelitian ini adalah penggunaan CPU, trafik, memori, dan disk pada computer server.

Adapun spesifikasi server yang digunakan dapat dilihat pada tabel 1.

Tabel 1. Spesifikasi Server

\begin{tabular}{|c|c|c|}
\hline No & Parameter & Spesifikasi \\
\hline $\mathbf{1}$ & Processor & Intel Core 2 Duo E7500 2.93 GHz \\
\hline $\mathbf{2}$ & Memory & 4 GB RAM DDR3 \\
\hline $\mathbf{3}$ & Harddisk & $320 \mathrm{~GB}$ \\
\hline
\end{tabular}

a. Hasil Pengukuran Server Linux

Hasil dari pengukuran terminal server dengan menggunakan server linux dapat dilihat pada tabel 2 .

Tabel 2. Hasil Pengukuran Terminal Server Linux

\begin{tabular}{|l|c|c|c|c|}
\hline Pengujian & CPU (\%) & Trafik (Mbps) & Memori (GB) & Disk (\%) \\
\hline \multicolumn{5}{|c|}{ Booting } \\
\hline 1 PC & 25 & 4.29 & 0.95 & 40 \\
\hline 5 PC & 40 & 24.99 & 1.75 & 54 \\
\hline 10 PC & 67 & 50.4 & 2.54 & 62 \\
\hline 15 PC & 93 & 75 & 3.2 & 95 \\
\hline \multicolumn{5}{|c|}{ Simulasi Jaringan 2 Router } \\
\hline
\end{tabular}




\begin{tabular}{|l|c|c|c|c|}
\hline 1 PC & 2 & 10.3 & 1.25 & 20 \\
\hline 5 PC & 8 & 15.34 & 1.75 & 45 \\
\hline 10 PC & 15 & 23.19 & 2.12 & 70 \\
\hline 15 PC & 24 & 49 & 3 & 90 \\
\hline \multicolumn{5}{|c|}{ Simulasi Jaringan 4 Router } \\
\hline 1 PC & 3 & 11 & 1.75 & 21 \\
\hline 5 PC & 9 & 17.45 & 2.15 & 49 \\
\hline 10 PC & 16 & 25.6 & 2.55 & 70 \\
\hline 15 PC & 28 & 50 & 3.2 & 92 \\
\hline \multicolumn{7}{|c|}{ Simulasi Jaringan 8 Router } \\
\hline 1 PC & 4 & 12.3 & 1.9 & 26 \\
\hline 5 PC & 13 & 20.89 & 2.5 & 60 \\
\hline 10 PC & 23 & 30.9 & 3.1 & 86 \\
\hline 15 PC & 36 & 40.1 & 3.8 & 100 \\
\hline
\end{tabular}

Berdasarkan pada Tabel 2, Dapat dilihat bahwa terjadi penggunaan disk 100\% pada simulasi Jaringan dengan menggunakan 8 buah router dengan jumlah PC client 15 . Kemudian pada kondisi tersebut penggunaan memori juga mencapai 3.8 GB. Dengan kata lain jika menggunakan 15 PC, maka kinerja server dapat dikatakan sudah maksimal. Dari tabel 1 juga dapat disimpulkan semakin bertambah jumlah PC client yang digunakan, maka resource server yang digunakan juga meningkat. Hal ini dikarenakan pc client mengambil data secara bersamasama pada server. Pada saat proses booting, peningkatan terjadi hanya saat kondisi server melakukan booting saja. Penggunaan resource semakin lama akan semakin berkurang. Dapat disimpulkan bahwa jika menggunakan server Linux, maka jumlah maksimal client yang dapat digunakan adalah sebanyak 15 PC.

b. Hasil Pengukuran Server Windows

Hasil dari pengukuran terminal server dengan menggunakan server windows dapat dilihat pada tabel 3 .

Berdasarkan pada Tabel 3, dapat dilihat bahwa terjadi penggunaan disk 100\% pada simulasi Jaringan dengan menggunakan 8 buah router dengan jumlah PC client 10 . Kemudian pada kondisi tersebut penggunaan memori juga mencapai 3.3 GB. Dengan kata lain jika menggunakan 10 PC, maka kinerja server dapat dikatakan sudah maksimal. Dari tabel 2 juga dapat disimpulkan semakin bertambah jumlah PC client yang digunakan, maka resource server yang digunakan juga meningkat. Hal ini dikarenakan pc client mengambil data secara bersamasama pada server. Pada saat proses booting, peningkatan terjadi hanya saat kondisi server melakukan booting saja. Penggunaan resource semakin lama akan semakin berkurang. Dapat disimpulkan bahwa jika menggunakan server Windows, maka jumlah maksimal client yang dapat digunakan adalah sebanyak 10 PC.

Berdasarkan hasil pengujian pada tabel 2 dan 3 dapat dilihat perbandingan penggunaan terminal server Linux dan Windows. Terminal server dengan menggunakan Windows lebih banyak memakan resource server dibandingkan dengan terminal server Linux. Dapat dilihat maksimal penggunaan client pada server windows yaitu 10 PC dan jumlah client pada server Linux berjumlah 15 PC. Selain dari sisi jumlah PC client yang lebih banyak, kelebihan menggunakan terminal Linux adalah system operasi linux yang open source, sehingga tidak ada biaya dalam penggunaan aplikasi Linux. Pada Windows ada biaya license untuk windows server dan aplikasi untuk menjalankan terminal servernya.

Tabel 3. Hasil Pengukuran Windows Terminal Server

\begin{tabular}{|l|c|c|c|c|}
\hline Pengujian & CPU (\%) & Trafik (Mbps) & Memori (GB) & Disk (\%) \\
\hline \multicolumn{5}{|c|}{ Booting } \\
\hline 1 PC & 40 & 3.67 & 1.2 & 60 \\
\hline 5 PC & 65 & 27.78 & 2.5 & 90 \\
\hline
\end{tabular}




\begin{tabular}{|l|c|c|c|c|}
\hline 10 PC & 89 & 53.76 & 3.7 & 100 \\
\hline \multicolumn{5}{|c|}{ Simulasi Jaringan 2 Router } \\
\hline 1 PC & 3 & 10.78 & 1.25 & 33 \\
\hline 5 PC & 15 & 16.45 & 1.9 & 49 \\
\hline 10 PC & 23 & 22.14 & 2.34 & 75 \\
\hline \multicolumn{5}{|c|}{ Simulasi Jaringan 4 Router } \\
\hline 1 PC & 5 & 12.23 & 1.75 & 36 \\
\hline 5 PC & 24 & 20.34 & 2.2 & 60 \\
\hline 10 PC & 35 & 26.12 & 2.80 & 85 \\
\hline \multicolumn{5}{|c|}{ Simulasi Jaringan 8 Router } \\
\hline 1 PC & 5 & 12.34 & 1.93 & 35 \\
\hline 5 PC & 26 & 21.56 & 2.76 & 78 \\
\hline 10 PC & 37 & 31.23 & 3.3 & 100 \\
\hline
\end{tabular}

\section{KESIMPULAN}

Berdasarkan hasil pengukuran yang telah dibahas sebelumnya maka dapat disimpulkan terminal server telah berjalan dengan baik, baik menggunakan Linux server ataupun Windows server. Penggunaan resource pada linux server lebih rendah daripada menggunakan Windows server. Hal ini dapat dilihat dari jumlah penggunaan maksimal client untuk server linux berjumlah 15 PC dan penggunaan maksimal client untuk server windows berjumlah 10 PC.

Untuk melaksanakan praktikum di Laboratorium yang berjumlah 30 PC maka dibutuhkan server dengan spesifikasi RAM minimal 8GB untuk server Linux dan RAM minimal 16 GB untuk server Windows. Kemudian dari sisi biaya menggunakan server linux tidak terdapat biaya dikarenakan sistem open source sedangkan server windows terdapat biaya license untuk windows dan aplikasi terminal servernya.

\section{Daftar Pustaka}

[1] Dinata, R. I., \& dkk, "A Cloud-based Virtual Computing Laboratory for Teaching Computer Network," in Cambridge-UK: IEEE Xplore Digital Library, 2012.

[2] Sumarto, et al, "Rancang Bangun Lab Computer Virtual Berbasis Cloud Computing Menggunakan Proxmox Pada Jaringan Terpusat," Politeknik Negeri Batam, 2015.

[3] Hartawan, I., \& Satwika, I, "Rancang Bangun Laboratorium Virtual Berbasis Cloud Computing Di Stmik Stikom Indonesia," in STMIK STIKOM INDONESIA (STIKI) Applied Sciences, vol. 7, pp. 54-60, 2016.

[4] Ali, H. A., \& El-Ghareeb, H. A, "Implementation of Cloud-based Virtual Lab for Educational Purpose," in Internasional Journal of Computer Science and Network Security, Vol. 14 No.7, 45-49, 2014.

[5] Manvar, D., Mishra, M., \& Sahoo, A, "Low Cost Computing Using Virtualization for Remote Dekstop," in 2012 Fourth International Conference on Communication Systems and Networks (COMSNETS 2012). Bangalore-India: IEEE, 2012.

[6] Prasetyo, A, "Perancangan dan Analisa Cloud Storage Infrastructure as Service dengan Kendali Raspberry Pi," in Jurnal Ilmiah NERO, vol. 2, no.1 pp. 27-35, 2015.

[7] Mell, P., \& Grance, T, The NIST Definition of Cloud Computing. Computer Security Division, Information Technology Laboratory, National Institute of Standards and Technology, United States Department of Commerce. Gaithersburg, MD 20899-8930: National Institute of Standards and Technology, 2011

[8] Ardian, Ferry, Perancangan Jaringan Computer Diskless Berbasis Windows - Linux Terminal Server Project (WLTSP) Pada Sistem Operasi Windows XP Professional dan Ubuntu 9.04. Bandung: Intitut Teknologi Telkom. 2011. 